\title{
Multilinguismo receptivo: um aliado das línguas menorizadas. O que é que o mirandês pode aprender da experiência frísia?
}

\author{
Receptive Multilingualism: an Ally for Minoritized Languages. \\ What Can Mirandese Learn from the Frisian Experience?
}

GUILlem BELMAR [guillem.belmar@gmail.com]

University of California, Santa Barbara, EE.UU.

SARA Pinho [sara.pinho@sapo.pt]

Rijksuniversiteit Groningen, Holanda

\begin{abstract}
RESUMO
Neste artigo sugerimos a inclusão de estratégias de assertividade linguística e práticas de multilinguismo receptivo nos projectos de revitalização de línguas menorizadas. Em concreto, comparámos as situações do frísio ocidental e do mirandês, e basando-nos nas semelhanças - a) as duas línguas têm uma falta de prestígio evidente embora sejam reconhecidas oficialmente pelos governos respectivos, e b) as duas línguas estão estreitamente relacionadas com a língua dominante respectiva- vamos propor uma estratégia para projectos de revitalização da língua mirandesa. Esta proposta, no entanto, pode também ser aplicável noutros contextos semelhantes, como, por exemplo, os das outras línguas românicas da península ibérica.
\end{abstract}

\section{Palavras-Chave}

Assertividade linguística; Multilinguismo receptivo; Revitalização linguística; frísio ocidental, mirandês.

\begin{abstract}
In this article we will suggest the inclusion of linguistic assertiveness strategies and receptive multilingualism practices in the revitalization projects of minoritized languages. In particular, we compared the situations of West Frisian and Mirandese, and based off the similarities between them - a) both languages suffer from an evident lack of prestige even when they are officially recognized by their respective governments, and b) both languages are closely related with the respective dominant language- we will suggest a strategy for the revitalization projects of Mirandese. This proposal, however, can also be applicable in other similar contexts, such as the situations of other Romance languages in the Iberian Peninsula.
\end{abstract}

\section{KEYWORDS}

Linguistic Assertiveness; Receptive Multilingualism; Language Revitalization; West Frisian; Mirandese

RECEBIDO 2019-10-30; ACEITE 2020-03-15 


\section{Introdução: a menorização e o multilinguismo receptivo}

For the most part, day in, day out, we are unfailingly polite. We grow up knowing our language isn't valued, that it's an inconvenience, that it's expensive, that it's asking too much. We never know in any given situation if someone's going to take against us in the workplace, in the street, in a pub, because we use it (Hornsby 2015: 15).

Esta situação é muito frequente nos contextos de línguas menorizadas. Esta incerteza faz com que a maioria dos falantes de línguas menorizadas interiorizem a inferioridade da sua língua. E é esta menorização, este complexo de inferioridade, que a maioria dos falantes de línguas menorizadas têm interiorizado durante muito tempo, e a razão principal da sua resistência em usar a língua menorizada com estranhos. Frequentemente, estes mudam para a língua dominante por uma questão de boa educação (ver Trosset 1986), para se acomodarem ao seu interlocutor. No entanto, em contextos minoritários esta acomodação é sempre para a língua maioritária: o falante da língua maioritária nunca sente a necessidade de se acomodar ao falante da língua menorizada. Em contextos de menorização, como no caso do frísio ocidental e do mirandês, a acomodação linguística implica, por defeito, mudar para a língua dominante — nestes casos, o holandês e o português, respectivamente (ver Belmar, Boven \& Pinho 2019 sobre o caso do frísio ocidental). A razão principal para esta diferença é a situação de diglossia na qual se encontram as línguas menorizadas: a acomodação ocorre sempre para a variedade linguística mais prestigiada. A questão é, portanto, se queremos aceitar esta diferença de prestígio ou se queremos combatê-la.

Geralmente, falamos a nossa língua menorizada apenas com aqueles que sabemos - ou assumimos - falam essa língua. Assim, os não-falantes não têm muitas possibilidades de ouvir a língua e, desta maneira, a língua menorizada torna-se gradualmente uma língua para um grupo de pessoas reduzido (ver Figura 1). Para quebrar este ciclo é necessário aceitar a legitimidade da prática de conversas bilingues ou mesmo multilingues, uma prática que poderia ajudar a reverter a substituição linguística (Belmar \& Pinho, em prelo).

Neste artigo, escolhemos usar o termo "menorizado" com o objetivo de reconhecer que a emergência de "minorias" foi uma consequência da formação dos estados-nação (Pujolar \& O’Rourke 2018; Belmar \& Glass 2019), e não uma característica intrínseca destas comunidades. Uma língua "menorizada" referir-se-á, de ora em diante, a uma língua que, independentemente do número de falantes, se encontra num estado constante de diglossia com a língua maioritária e "cujo valor não é reconhecido nas interacções pelos falantes de uma língua sociolinguisticamente dominante" (Kasbarian 1997: 188).

\section{A menorização linguística e o contexto sociolinguístico actual do frísio ocidental e do mirandês}

As línguas menorizadas são frequentemente associadas com a vida rural, com o facto de não fazerem parte da modernidade (Pietikäinen \& Kelly-Holmes 2011) e mesmo com o facto de não estarem preparadas para as necessidades da vida moderna (ver Aguilar-Amat \& Santamaria 1999). Isto reforça a posição das línguas dominantes como as únicas línguas que garantem o acesso à 


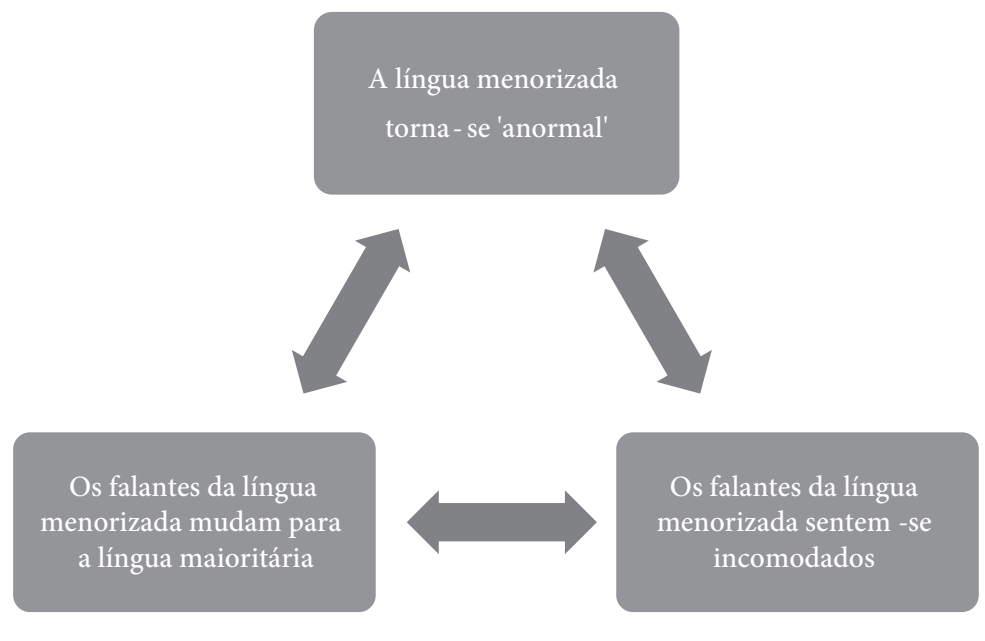

Figura 1: O ciclo da menorização linguística nas interacções comunicativas

modernidade, como as únicas ferramentas para a mobilidade social (Pujolar \& O’Rourke 2018) e, como tal, como as únicas línguas com incentivos económicos para os falantes. A menorização linguística é, de facto, uma consequência da série de processos homogeneizadores dos estados-nação. Estes processos homogeneizadores, altamente relacionados com o conceito de 'modernização', condenaram todas as línguas não estatais a um estado de diglossia permanente, e excluíram-nas, de propósito, da 'modernidade' (O’Rourke, Pujolar \& Ramallo 2015). É por isso que muitos falantes de línguas menorizadas não transmitiram a sua língua aos seus filhos, e mudaram para a língua estatal em busca de novas oportunidades. Mas é importante enfatizar que os membros das comunidades menorizadas sofreram diferentes tipos de discriminação, incluindo a discriminação linguística. Às vezes foi uma política 'não-política' (Fishman 2001: 454); mais frequentemente os estados exerceram políticas de vergonha, desnaturalização e de sentimentos de ódio internalizados através da estigmatização, castigos físicos, colégios internos forçados para os jovens rapazes, encarceração, repressão ou mesmo deportação das comunidades menorizadas. Por outras palavras, a decisão de não transmitir a língua à geração seguinte nunca é uma decisão voluntária: é o resultado de décadas (ou mesmo séculos) de marginalização sistemática.

\section{O frísio ocidental (Frysk)}

O frísio ocidental é uma língua menorizada, a qual é falada na província da Frísia, no norte dos Países Baixos, assim como em algumas aldeias vizinhas na província de Groningen. O frísio não é a única língua falada na província. Falam-se também o bildts e o frísio das cidades (variedades classificadas como uma mistura de frísio e holandês), o hylpers (uma variedade conservadora da língua frísia), o baixo saxão (nas áreas vizinhas a Drenthe e Groningen), o holandês e, mais recentemente, o inglês e as línguas dos migrantes mais recentes. 
O frísio, com cerca de meio milhão de falantes $(485,000)$, é a língua nativa de $54 \%$ da população da Frísia (Provinsje Fryslân 2015), e é reconhecido como uma das línguas oficiais dos Países Baixos na Constituição Holandesa (Laanen 2001). No entanto, as atitudes negativas relativamente ao frísio parecem servir de base ao nível de dificuldade aparente que é muitas vezes usado como a razão para evitar o uso da língua na esfera pública (Ytsma 1995; Ytsma 2007; Swarte 2011; Hilton \& Gooskens 2013; Belmar 2018; Belmar 2019a). Geralmente, quando as atitudes para com uma língua são negativas, os não-falantes dessa língua tendem a considerá-la 'difícil' (ver Wolff 1959; Giles \& Niedzielsky 1998). Outro exemplo do impacto das atitudes negativas é que mesmo os falantes nativos consideram de má educação falar frísio com alguém que esteja a falar holandês (ver Wolf 2013), o que tem um efeito negativo visível no uso da língua e na motivação para aprendê-la (Belmar et al 2019).

\section{O mirandês (mirandés)}

O mirandês, por outro lado, é uma das variedades —ou línguas- do contínuo astur-leonês. É também uma língua menorizada - entre 4.000 e 10.000 falantes- e é falada no concelho de Miranda do Douro, no nordeste de Portugal, na fronteira com Espanha. O português não começou a predominar na comunidade até a década de 1950 (Hargitai 2014: 1).

O mirandês é a única variedade deste contínuo linguístico falada em Portugal, e também é a única variedade reconhecida como língua oficial na sua área. As variedades faladas em comunidades do Estado Espanhol —o asturiano, o leonês, o cântabro e o estremenho- não são consideradas línguas oficiais, embora algumas sejam protegidas por leis regionais.

Portugal é frequentemente mencionado como um exemplo de país monolingue (e.g., Nelde 1978: 27: "Todos os estados europeus são multilingues com as excepções de Portugal e Islândia”"1), mas, na realidade, isto não é verdade. Em Portugal falam-se tradicionalmente, além do português, o mirandês (ver Hargitai 2014), a língua gestual portuguesa (ver Silva 2017) e, desde o século dezoito, o minderico (ver Ferreira 2016). Hoje em dia também são faladas outras línguas. No entanto, o português e o mirandês são as duas únicas línguas oficiais da República Portuguesa ${ }^{2}$, desde o ano 1999:

Cula lhei $\mathrm{n}^{\mathrm{a}} 7 / 99$, de Jineiro de 1 anho 1999, la lhéngua mirandesa passa a ser tamien oufecial en Pertual. Ye reconhecido 1 dreito de que la lhéngua seia ansinada nas scuolas adonde haba alunos anteressados an daprender-la, que eilha seia outilizada nas anstituçones de 1 Stado lhocalizadas ne 1 cunceilho de Mirande de 1 Douro, i que 1 Stado Pertués apoio 1 sou zambolbimiento, promoçon i dibulgaçon, atrabéç 1 apoio a las ambestigaçones científicas i a la formaçon de nuobos porsores que téngan cundiçones de ansinar la lhéngua (Quarteu \& Frías Conde 2002: 90).

1 "Ausser Portugal und Island sind alle europäischen Staaten mehrsprachig"

2 Em 2008, uma lei reconheceu o direito das pessoas surdas à educação bilingue (em português e em língua gestual portuguesa - LGP) 
Os falantes de mirandês, portanto, têm o direito de aprendê-lo na escola — se houver alunos interessados- e de usá-lo com as instituições regionais. O estado, pela sua parte, deve facilitar o desenvolvimento da língua, a sua promoção e estudo científico, assim como a formação de professores.

\section{(Mútua) inteligibilidade entre línguas estreitamente relacionadas}

A inteligibilidade de línguas intimamente relacionadas (ver Bezooijen \& Gooskens 2007; Gooskens 2013; Gooskens, Heuven, Golubović, Schüppert, Swarte \& Voigt 2018) tem sido objecto de estudo durante muito tempo, especialmente entre línguas maioritárias dentro de contínuos estabelecidos de variedades linguísticas estreitamente relacionadas (ver Gooskens \& Heuven 2017). De facto, a maior parte da literatura disponível sobre inteligibilidade concentra-se nas línguas escandinavas (e.g., Gooskens 2011), nas línguas eslavas (e.g., Golubović \& Gooskens 2015), nas línguas românicas (e.g., Araújo, Hidalgo, Melo-Pfeifer, Séré \& Vela 2009; Fonseca 2012) e nas línguas germânicas ocidentais (e.g., Bezooijen \& Berg 1999a; Bezooijen \& Berg 1999b; Bezooijen \& Berg 1999c; Gooskens \& Heeringa 2004; Bezooijen \& Gooskens 2005; Gooskens, Bezooijen \& Heuven 2015; Swarte 2016; Belmar \& Pinho, em prelo). No entanto, os factores que contribuem para a inteligibilidade ainda não são completamente compreendidos. Gooskens (2007) sugeriu que a distância fonética tem um efeito maior na inteligibilidade do que a distância lexical, mas é possível que isto só seja verdade para idiomas que compartilham uma grande percentagem de itens lexicais de entrada. Além disso, estudos anteriores mostraram um impacto de factores extra-linguísticos, como contacto, instrução e atitude, embora fracos e difíceis de provar (ver Gooskens 2006; Gooskens \& Bezooijen 2006).

Além disso, o estudo da inteligibilidade, ou da facilidade de compreensão, sempre esteve vinculado ao estudo da comunicação numa sociedade multilingue. A semi-comunicação (ou semi-entendimento) (Haugen 1996; ver também Braunmüller \& Zeevaert 2001; Zeevaert 2007) postula que, para que a comunicação seja bem-sucedida, os participantes não precisam de compartilhar exatamente a mesma língua. De facto, Haugen chega ao ponto de afirmar que "despite the growing loss of efficiency in the communication process as language codes deviate, it is often astonishing how great a difference speakers can overcome if the will to understand is there" (Haugen 1996: 280). Na realidade, a vontade de fazer um esforço para entender com sucesso o interlocutor parece ser um factor chave na determinação da inteligibilidade.

Outros académicos vincularam a inteligibilidade com a competência receptiva. Escrevendo sobre o contexto suíço, Lüdi (2007), por exemplo, afirmou que uma assimetria entre a competência produtiva e receptiva deve promover a comunicação multilingue. Da mesma forma, Berthele (2007) declarou que a intercompreensão é uma habilidade que requer prática (ver, por exemplo, Bergsma, Swarte \& Gooskens 2014), que os mal-entendidos são normais e comuns neste tipo de interacções comunicativas, mas que esses são corrigidos à medida que a conversa continua e os participantes percebem erros anteriores (ver também Grin 2008). Outros investigadores optaram por aproveitar ao máximo a inteligibilidade, sugerindo o multilinguismo receptivo - ou a possibilidade de uma conversa em que os participantes falam línguas diferentes - como uma opção na comunicação multilingue (Blees, Mak \& ten Thije 2014; ver também ten Thije \& Zeevaert 
2007; Beerkens \& ten Thije 2011; Rebhein, ten Thije \& Verschil 2012). De facto, Swarte, Hilton e Gooskens (2013), num estudo sobre a inteligibilidade entre frísio ocidental e frísio septentrional, sugerem que uma percentagem de $38 \%$ de intercompreensão seria suficiente para compreender direcções numa outra língua.

\section{Inteligibilidade entre frísio e holandês}

No caso do frísio e do holandês, apenas podemos estudar a inteligibilidade do frísio para os falantes de holandês, já que todos os falantes de frísio falam também holandês. Além disso, investigadores dizem que o frísio se encontra num processo de convergência com o holandês padrão (ver Haan 1997; Nerbonne 2001), e estudos recentes demonstraram o alto nível de inteligibilidade entre o frísio e outras línguas e dialectos regionais da Holanda e da Flandres (ver Bezooijen \& Berg 1999c; Bezooijen \& Gooskens 2005; Vries 2010; Belmar \& Pinho, em prelo).

De acordo com o estudo de Belmar e Pinho (em prelo), o frísio é altamente inteligível para os falantes nativos de holandês (como sugerem Bezooijen \& Berg 1999c; Vries 2010). Os resultados parecem sugerir também que falar uma outra variedade germânica regional além do holandês não tem nenhum impacto sobre a capacidade de perceber o frísio (ao contrário do que se poderia esperar com base nos resultados de estudos anteriores). Resultados muito importantes, porque significa que todos os falantes de holandês, independentemente das variedades germânicas que conhecem, podem perceber o frísio se a vontade estiver lá, o que os autores usam como base para a sua conclusão principal: as conversas bilingues são a chave para promover o uso do frísio, especialmente nas cidades.

\section{Inteligibilidade entre mirandês e português}

No caso do mirandês, esta língua faz parte do grupo das línguas ibero-românicas, as quais são estreitamente relacionadas (ver Araújo et al. 2009; Bautista 2016). O astur-leonês encontra-se a meio caminho entre o contínuo galego-português e o espanhol, e o mirandês é a variedade mais ocidental deste domínio linguístico - "Hoije, considera-se que 1 mirandés ye ũa bariedade de 1 grupo oucidental de 1 dominio lhenguístico asturo-lheonés" (Quarteu \& Frías Conde 2002: 90). As diferenças entre o mirandês e as outras variedades do domínio linguístico astur-leonês são o resultado do contacto com as línguas dominantes das diferentes regiões: “[...] las diferéncias más amportantes antre 1 mirandés i 1 asturiano [...] stan relacionadas culas anfluenças de las suas lhénguas de cuntato, 1 pertués i l castelhano" (Quarteu \& Frías Conde 2002: 90). A estreita relação genética das línguas e a grande influência do português que recebeu o mirandês (Quarteu \& Frías Conde 2002) faz com que as duas línguas sejam hoje altamente intercompreensíveis.

No entanto, parece não haver um estudo que meça a inteligibilidade do mirandês para falantes de português. Sugerimos que se poderia realizar um estudo tendo como modelo o que realizámos em Fryslân (ver Belmar \& Pinho, to appear), adaptando-o ao contexto mirandês e com o objectivo de usar os resultados para começar a construir estratégias para fomentar 
o multilinguismo receptivo e a assertividade linguística, o que poderia ser usado em campanhas de promoção da língua mirandesa.

\section{Projecto “Twatalige konversaasjes"}

Em colaboração com a Universidade de Groningen e a Afûk —a organização para a promoção da língua frísia-, desenhámos uma série de 'workshops' de assertividade linguística com voluntários linguísticos e funcionários da câmara municipal de Waadhoeke. Além dos workshops, os participantes responderam a um questionário sobre atitudes e uso linguístico —em diferentes situações, mas especialmente no trabalho. Umas semanas depois do workshop, os participantes responderam a um outro questionário semelhante, no qual também perguntámos sobre a sua experiência com conversas bilingues desde o workshop. A nossa pesquisa queria responder a) se uma pequena intervenção sobre a assertividade linguística e o multilinguismo receptivo pode ter um impacto no uso do frísio; e b) se a exposição (curta) a línguas estreitamente relacionadas pode ter um impacto nas atitudes e no uso da língua menorizada por parte dos falantes da língua maioritária — no contexto frísio, o holandês.

\section{Enquadramento teórico}

Nesta secção vamos apresentar os conceitos chave que usámos para o enquadramento teórico deste projecto. Baseámo-nos na translinguagem (ver Cenoz \& Gorter 2017), na multicompetência (ver Cook 1991), na interdependência (ver Cummins 1981), no bilinguismo horizontal (ver Baetens 1986), na consciência linguística (ver Hélot 2012), no multilinguismo receptivo e na inteligibilidade (ver a secção anterior), e na assertividade linguística (ver Suay \& Sanginés 2010).

\section{Translinguagem}

A translinguagem refere-se ao modo de expressar e processar o pensamento através do uso de duas ou mais línguas (ver Baker 2011; Poza 2017). Postula-se que os diferentes sistemas de comunicação que uma pessoa conhece formam um sistema único e integrado, onde as línguas são códigos fluídos que os falantes enquadram nas suas práticas sociais (ver Cenoz \& Gorter 2017). Concentra-se nas práticas linguísticas de pessoas multilingues, não monolingues, e entende-as como a norma. $\mathrm{O}$ foco está nas estratégias dos falantes para conseguir uma comunicação eficaz, com ênfase em particular nos modos como selecionam certas características do seu repertório linguístico para se expressar (Velasco \& García 2014: 7; cf. Lewis, Jones \& Baker 2012). Para o estudo da menorização linguística, é especialmente importante o facto que a translinguagem apaga as hierarquias linguísticas e os limites entre línguas (García \& Leiva 2014): todas as variedades linguísticas são concebidas como iguais e o uso de diferentes línguas ou os usos linguísticos híbridos são considerados a norma. 


\section{Multicompetência}

No estudo do bilinguismo, é amplamente aceite que a L1 do indivíduo influencia a aquisição de qualquer língua estrangeira. No entanto, essa influência - chamada transferência- não é unidirecional, e a L1 do falante bilingue apresenta recursos que a diferenciam da L1 dos falantes monolingues. Na verdade, o termo multicompetência (ver Cook 1991 e 1992) foi sugerido para explicar, entre outros aspectos, a transferência multidirecional em multilingues. A multicompetência sugere que todas as línguas do indivíduo formam um super-sistema, e não uma coleç̧ão de sistemas completamente isolados (ver também Rothman, Cabrelli \& Boot 2013). Portanto, com a aquisição de qualquer língua estrangeira, a possibilidade de mudanças no super-sistema -e, assim, nos subsistemas das específicas línguas na mente do indivíduo multilingue-crescem exponencialmente.

Para nós, é importante enfatizar que a aquisição de uma língua menorizada - mesmo que seja apenas a aquisição de habilidades passivas - não requer um novo sistema linguístico para quem fala uma língua dominante, especialmente uma que esteja estreitamente relacionado com a língua menorizada em questão. Pelo contrário, apenas expande o actual sistema linguístico do falante e, devido à proximidade dessas línguas, o esforço é muito menor do que se poderia esperar.

\section{Interdependência}

A hipótese da interdependência, semelhante à da multicompetência, afirma que o conhecimento linguístico, ou de qualquer tipo, que tenha sido adquirido com sucesso em qualquer idioma, pode ser transferido para qualquer outro idioma, sempre que haja exposição adequada e a motivação para aprender a língua esteja lá (ver Cummins 1981; 1991 e 2001). Portanto, como a maior parte do seu conhecimento linguístico pode ser facilmente transferido para a língua de destino, os falantes de holandês (ou português) poderiam adquirir o frísio (ou o mirandês) com relativa facilidade. Além disso, a disseminação de conversas bilingues pode ajudar a aumentar a exposição à língua menorizada que os falantes da língua maioritária têm, o que facilitaria a aquisição da língua menorizada.

\section{Bilinguismo horizontal}

O bilinguismo social ocorre quando duas línguas são comuns numa sociedade em concreto, na qual a maioria dos membros é competente - em graus variados-em ambas línguas. Essas duas línguas podem ser usadas de forma permutável por qualquer falante a qualquer momento, mas são mais comumente associadas a determinadas circunstâncias.

No entanto, o bilinguismo social quase nunca é assim. Podemos dividi-lo em bilinguismo horizontal e bilinguismo vertical -este último é mais conhecido como diglossia. O bilinguismo horizontal desenvolve-se quando as duas línguas têm um estatuto equivalente na vida oficial, cultural e familiar de um grupo de falantes. No entanto, o bilinguismo social geralmente deriva em diglossia, ou a situação na qual duas línguas coexistem e são usadas no mesmo ambiente, mas em circunstâncias diferentes (ver Baetens 1986; Yuko \& Kenji 2004). 
Isto é, existe uma diferenciação entre variedade alta ou prestigiada e variedade baixa. Segundo Ferguson (1959), a especialização da função para a variedade alta e para a variedade baixa determina a adequação de qualquer uma das variedades para um conjunto de situações, com poucas ocasiões de sobreposição. Essa distinção, extremamente comum em contextos minoritários, é mantida sucessivamente porque os falantes consideram que a variedade alta é mais prestigiada, mais atraente e mais apropriada do que a variedade baixa, que costuma ser vista como um obstáculo para a mobilidade social.

\section{Consciência linguística}

O conhecimento explícito sobre a língua e a percepção consciente e a sensibilização através do ensino, na aprendizagem e no uso da língua (como Hélot 2012 descreve a consciência linguística) têm como objectivo estimular a curiosidade sobre a(s) língua(s) integrando diferentes abordagens ao ensino de línguas e ajudando as pessoas na aprendizagem de línguas estrangeiras. O nosso projecto, portanto, pode ser enquadrado como uma estratégia de consciência linguística, na qual a exposição à língua menorizada pode provocar curiosidade, o que pode ajudar a sua aquisição.

\section{Assertividade linguística}

Qualquer interacção comunicativa é stressante, e isto é especialmente verdade para os falantes de línguas menorizadas. A incerteza está sempre lá quando começam uma nova conversa, e não sabem se é possível ou mesmo apropriado usar a língua nesse contexto. O motivo é que, em contextos de línguas menorizadas, a língua maioritária domina (quase) todos os usos linguísticos. Para os falantes da língua maioritária, a sua língua é de uso normal, incontestável, independentemente da situação em que se encontram (Suay 2016). Infelizmente, não podemos dizer o mesmo dos falantes de línguas menorizadas, já que a sua língua geralmente se torna um identificador de pertença a um certo grupo, e não uma ferramenta 'normal' de comunicação. É por isso que a língua menorizada é frequentemente só usada com pessoas que sabemos —ou assumimos - que também a falam.

Suay e Sanginés (2010) sugerem a assertividade linguística como um exercício que os falantes de línguas menorizadas podem praticar para quebrar esse círculo vicioso. Suay (2016) descreve a assertividade linguística como um "acto de coerência”, um acto de exercício dos direitos em vez de defendê-los em discursos elaborados. Ao usar a língua menorizada para iniciar qualquer interacção comunicativa na qual uma pessoa se possa envolver - ou seja, usando-a como a ferramenta 'normal' de comunicação-, estará a defender o seu próprio direito de a falar. E, no entanto, Suay (2016) (ver também Suay \& Sanginés 2010) não sugere que se deva coagir o interlocutor a usar a mesma língua, nem sugere que se insista em usar essa língua, independentemente do quão bem-sucedida a troca comunicativa esteja a ser. Pelo contrário, ele defende o reconhecimento do direito de cada interlocutor de falar a língua que preferir, e admite que há situações em que alguém pode ter que mudar para uma língua dominante para garantir a comunicação. 
Na realidade, Suay e Sanginés (2010) sugerem que existem três tipos de falantes de línguas menorizadas: a) falantes proactivos, que iniciam a interacção na língua maioritária; b) falantes reactivos, que começam na língua menorizada mas mudam para a maioritária se a outra pessoa tiver dificuldades com a língua menorizada ou se a outra pessoa responder na língua maioritária; e c) falantes resistentes, que insistem em usar a língua menorizada e só mudam para a maioritária se lhes for pedido especificamente. Observe que os autores não sugerem que os falantes de línguas menorizadas tenham que acabar com todas as regras de acomodação ou educação, mas devem dar crédito aos seus interlocutores e deixar que decidam eles mesmos se a mudança para a língua maioritária é necessária. Falar uma língua menorizada não é rude. O que é rude é supor que os nossos interlocutores não são suficientemente inteligentes para entender uma língua que seja semelhante à sua e à qual tenham sido expostos.

\section{Workshops e questionários usados na experiência frísia}

Os workshops começaram com uma introdução e os participantes receberam um questionário pre-workshop. De seguida, foi passada uma caixa de ferramentas e foi pedido aos participantes que retirassem um objecto desta. Depois de terem pegado numa das ferramentas, o instrutor pedia a cada participante que dissesse qual tinham escolhido e explicasse o porquê dessa escolha e de que maneiras essa ferramenta específica se poderia relacionar com a sua relação com a língua materna. Isto levou a uma conversa durante a qual os participantes compartilharam experiências nas quais tiveram que mudar para uma outra língua (na sua maioria, o holandês) e a uma reflexão em grupo sobre o porquê de isso ter acontecido e de como isso os fez sentir. Após um breve intervalo, o instrutor apresentou o enquadramento teórico da nossa pesquisa, com base em Suay (2016) e Suay e Sanginés (2010), além de estudos realizados sobre a inteligibilidade entre holandês e frísio por Belmar e Pinho (em prelo). Esta apresentação teve como objectivo fornecer algumas ferramentas para praticar a assertividade linguística em Fryslân, vinculando as suas próprias experiências com teorias mais amplas, experiências noutros contextos, estatísticas da província da Frísia e estudos sobre o efeito que a mudança automática para o holandês tem na motivação na aprendizagem de alunos de frísio (ver Belmar et al. 2019). Os workshops terminaram com uma discussão sobre as maneiras como a assertividade linguística pode ser aplicada à nossa vida quotidiana e o possível impacto que esta pode ter no uso do frísio - ou de qualquer outra língua menorizada.

\section{Possível aplicação no contexto mirandês}

A aplicação destas estratégias no contexto mirandês poderia ser o começo da inclusão de conversas bilingues nas campanhas de promoção linguística na região. A nossa recomendação é começar por fazer um estudo que meça o nível de inteligibilidade da língua mirandesa para os falantes de português. É de esperar que a intercompreensão entre as duas língua seja muito elevada — talvez com percentagens próximas dos $80 \%$ - mas é sempre aconselhável ter os resultados de um estudo para convencer as pessoas que se recusam a aceitá-lo. Este estudo não envolve muitas dificuldades e pode ser feito pela internet com questionários online (ver Belmar \& Pinho, em prelo). 


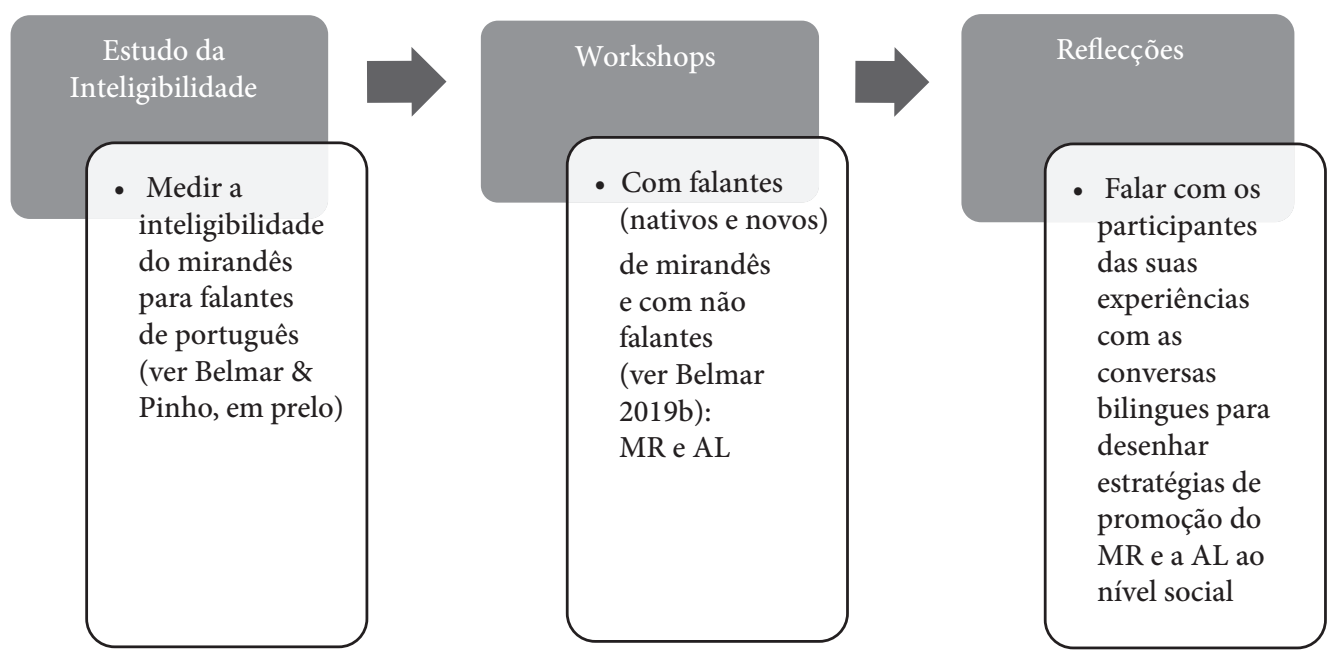

Figura 2: Sugestão para a promoção de conversas bilingues e o desenvolvimento de workshops de multilinguismo receptivo (MR) e assertividade linguística (AL) no contexto do mirandês

É importante, no entanto, que os exercícios incluam exemplos do mirandês escrito e do mirandês falado, e os temas de conversa sejam comuns — para evitar resultados baixos que não reflectiriam a realidade.

O passo seguinte é a organização de workshops de multilinguismo receptivo e assertividade linguística em Miranda do Douro. Estes workshops podem ser desenhados com o exemplo da experiência frísia descrita neste artigo (mais informação em Belmar 2019b). É necessário que os workshops incluam participantes de origens diferentes. A inclusão de falantes nativos, novos falantes e não falantes é crucial para a representação da realidade social da língua. Também é possível começar por se focar numa área concreta e trabalhar primeiramente com professores, ou com jornalistas, ou com pessoas que trabalham no comércio local.

Finalmente, os organizadores dos workshops devem manter o contacto com os participantes e recolher as suas reflecções sobre a experiência com conversas bilingues. É aconselhável, também, organizar mais do que um workshop com os diferentes participantes, e concentrar-se em diferentes áreas à medida que precisem delas. Este feedback é absolutamente necessário para poder desenhar estratégias mais amplas para promover o multilinguismo receptivo e a assertividade linguística ao nível social com o objectivo de normalizar as conversas bilingues.

\section{Conclusões}

A experiência frísia permitiu observar as reacções dos participantes às noções de multilinguismo receptivo e de assertividade linguística. As razões pelas quais os falantes de frísio não usam a sua língua com estranhos são principalmente o medo de não serem entendidos e a crença de que 
a acomodação à língua dominante é um sinal de boa educação. A primeira razão foi amplamente documentada como um impedimento para que os falantes de línguas menorizadas usem a sua língua (ver, por exemplo, Belmar, em prelo, sobre o uso de línguas menorizadas nas redes sociais) e pode ser atribuída a estratégias de desenho de audiência (ou 'audience design', ver Marwick \& Boyd 2011). Isto foi um conceito cunhado em estudos dos media que se refere ao processo pelo qual os falantes planeiam as características das suas mensagens antes de as emitir, com base no público que assumem irá recebê-las. Por outras palavras, o estatuto da língua dominante como a língua 'normal' de comunicação, a língua não-marcada, faz com que os falantes a favoreçam em relação ao uso de línguas menorizadas. Estas geralmente são consideradas apenas um meio de comunicação com um público específico (ver Belmar \& Glass 2019).

Quanto à acomodação como um sinal de cortesia, há muito tempo que se argumenta que os falantes de línguas menorizadas mudam para a língua dominante para serem bem educados com o seu interlocutor (ver, por exemplo, Trosset 1986). No entanto, estudos mais recentes sobre novos falantes de línguas menorizadas sugerem que essa estratégia pode, na realidade, ser entendida pelos falantes de línguas maioritárias como uma restrição do acesso às línguas menorizadas (ver, por exemplo, O’Rourke \& Ramallo 2013; O’Rourke \& DePalma 2016; Belmar et al. 2019). Ou seja, uma prática que os marca como estranhos à comunidade e que os impede de se familiarizarem com a língua menorizada. As sugestões de Suay e Sanginés (2010) para a assertividade linguística indicam que esses casos devem ser abordados em campanhas de revitalização, com workshops que podem transformar os falantes proactivos em falantes resistentes, o que quebraria os padrões diglóssicos observados nos contextos menorizados (ver Ferguson 1959). Convém lembrar que Suay (2016) (e também Suay \& Sanginés 2010) não defende o uso indiscriminado da língua menorizada em todos os contextos e com todos os interlocutores sem ter em consideração a quantidade de informação transmitida com sucesso. Pelo contrário, eles admitem que há situações em que alguém pode ter que mudar para uma língua dominante para garantir a comunicação, seja por interesse pessoal —ou seja, a necessidade de transmitir uma mensagem - ou por boa educação - deferência em relação ao interlocutor.

Acreditamos que, se as línguas menorizadas fossem mais visíveis nas ruas, assim como mais usadas em eventos públicos (seja ao lado da língua dominante ou exclusivamente), o prestígio destas línguas poderia aumentar e os falantes das línguas dominantes poderiam ter a oportunidade de melhorar o conhecimento (Belmar \& Pinho, em prelo), neste caso, da língua mirandesa. Como consequência, poder-se-ia criar um espaço seguro onde as duas línguas pudessem ser usadas igualmente. Ou seja, consideramos que é necessário (e completamente viável) que as administrações locais promovam estratégias para capacitar os falantes de línguas menorizadas a usar a sua língua, mesmo em conversas com falantes da língua dominante. Somente assim pode a sociedade alcançar o bilinguismo social, e não a situação diglóssica que encontramos actualmente na maioria dos casos (Belmar 2019b; Belmar \& Pinho, em prelo).

Para terminar: Se falam mirandês, catalão, galego, asturiano, leonês, aragonês, português ou espanhol (ou outra língua românica), usem a língua que preferirem, a língua com a qual se sentem mais confortáveis. Falem a língua que escolherem, e deixem os outros falarem a língua que eles quiserem. 


\section{Referências bibliográficas}

Aguilar-Amat, A.; \& Santamaria, L. (1999). Terminologia i llengües minoritzades. Quaderns. Revista de Traducció, 3, 101-112.

Araújo, M. H.; Hidalgo, R.; Melo-Pfeifer, S.; Séré, A.; \& Vela, C. (Eds.). (2009). A intercompreensão em línguas românicas: conceitos, práticas, formação. Aveiro: Galapro

Baetens, B. H. (1986). Bilingualism: basic principles. Clevedon: Multilingual Matters.

Baker, C. (2011). Foundations of bilingual education and bilingualism. Bristol: Multilingual Matters.

Bautista, A.G. (2016). Contributo para uma história do asturo-leonês em Portugal / Contribution to a history of Astur-Leonese in Portugal. Lletres Asturianes, 115, 89-102.

Beerkens, R.; \& ten Thije, J. D. (2011). Receptive Multilingualism in the Dutch-German Border Area. In J. N. Jørgensen (Ed.), A Toolkit for Transnational communication in Europe - Copenhagen studies in bilingualism, 64, 102-140.

Belmar, G. (2018). New speakers of a minoritized language: motivation, attitudes and langauge use of 'nije sprekkers' of West Frisian. Tese de mestrado, Rijksuniversiteit Groningen.

. (2019a). Attitudes and language use of (potential) new speakers of a minoritized language: the case of adults learning West Frisian in formal courses. Sustainable Multilingualism, 15, 170-188.

. (2019b). How to use linguistic assertiveness and receptive multilingualism in language revitalization. Guest talk at the graduate student seminar of the Spanish Department of the University of California, Santa Barbara. <https://www.academia.edu/40734996/How_to_use_Linguistic_Assertivess_and_Receptive_Multilingualism_in_Language_Revitalization>

- (em prelo). Digital presence and language revitalization: attitudes towards and use of minority languages on social media. In Sciriha, L. (Ed.), Comparative Studies in Bilingualism and Bilingual Education. Cambridge: Cambridge Scholars Publishing.

Belmar, G.; Boven, C. van; \& Pinho, S. (2019). Why do adults decide to learn a minority language? A study of the motivation(s) of potential new speakers of West Frisian. Sustainable Multilingualism, 14, 1, 138-151.

Belmar, G.; \& Glass, M. (2019). Virtual communities as breathing spaces for minority languages: re-framing minority language use in social media. Adeptus, 14, 1-24.

Belmar, G.; \& Pinho, S. (em prelo). 'Kinsto it Frysk ferstean?' Intelligibility of West Frisian for Dutch native speakers. Dutch Journal of Applied Linguistics.

Bergsma, F.; Swarte, F.; \& Gooskens, C. (2014). Does instruction about phonological correspondences contribute to the intelligibility of a closely related language. Dutch Journal of Applied Linguistics, 3, 1, 45-61.

Berthele, R. (2007). Zum Prozess des Verstehens und Erschließens. In B. Hufeisen, \& N. Marx (Eds.), EuroComGerm - Die sieben Siebe: Germanische Sprachen lesen lernen (pp. 15-26). Aachen: Shaker Verlag.

Bezooijen, R. van; \& Berg, R. van den (1999a). Taalvariëteiten in Nederland en Vlaanderen: hoe staat het met hun verstaanbaarheid? Taal en Tongval L1, 1, 15, 33.

. (1999b). Word intelligibility of language varieties in the Netherlands and Flanders under minimal conditions. Linguistics in the Netherlands, 1-12.

. (1999c). Verstaanberheid van het Gronings, Fries, Limburgs and West-Vlaams: waar zitten de problemen. Em Artikelen van de Derde Sociolinguïstiche Conferentie (pp. 49-60). Lunteren. Delft: Eburon.

Bezooijen, R. van; \& Gooskens, C. (2005). How easy is it for speakers of Dutch to understand Frisian and Afrikaans, and why? In Linguistics in the Netherlands (pp. 13-24). Amsterdam: John Benjamins. 
. (2007). Interlingual text comprehension: linguistic and extralinguistic determinants. In J. D. tem Thije \& L. Zeevaert (Eds.), Receptive multilingualism and intercultural communication: linguistic analysis, languages, policies and didactic concepts (pp. 249-264). Amsterdam: John Benjamins.

Blees, G. J.; Mak, W.M.; \& ten Thije, J. D. (2014). English as a lingua franca versus lingua receptiva in problem-solving conversations between Dutch and German students. Applied Linguistics Review, 5, 1, 173-193.

Braunmüller, K.; \& Zeevaert, L. (2001). Semikommunikation, rezeptive Mehrsprachigkeit und verwandte Phänomene. Eine bibliographische Bestandsaufnahme. Arbeiten zur Mehrsprachigkeit - Folge B, nr. 19, Universität Hamburg.

Cenoz, J.; \& Gorter, D. (2017). Minority languages and sustainable translanguaging: threat or opportunity? Journal of Multicultural Development, 38, 1, 901-912.

Cook, V. J. (1991). The poverty-of-the-stimulus argument and multi-competence. Second Language Research, $7,2,103-117$.

- (1992). Evidence for multi-competence. Language learning, 42, 4, 557-591.

Cummins, J. (1981). Empirical and theoretical underpinnings of bilingual education. Journal of Education, $163,1,16-29$.

. (1991). Interdependence of first- and second-language proficiency in bilingual children. In E. Bialystok (Ed.), Language processing in bilingual children (pp. 70-89). Cambridge: Cambridge University Press.

. (2001). Fundamental Psycholinguistic and Sociological Principles Underlying Educational Success for Linguistic Minority Students. In T. Skutnabb-Kangas, R. Philipson, A.K. Mohatny, \& M. Panda (Eds.), Social Justice Through Multilingual Education (pp. 19-35). Bristol: Multilingual Matters.

Ferguson, C. A. (1959). Diglossia. Word, 15, 325-340.

Ferreira, V. (2016). New speakers of Minderico: Dynamics and tensions in the revitalization process. Language Documentation and Conservation, 9, 26-37.

Fishman, J. (2001). From theory to practice (and vice versa): review, reconsideration and reiteration. In J. Fishman (Ed.), Can threatened languages be saved? Reversing language shift, revisited: a $21^{\text {st }}$ century perspective (pp. 451-483). Clevedon: Multilingual Matters.

Fonseca, M. (2012). Apprendre par le plurilinguisme: exploration du carrefour entre intercompréhension en langues romanes et enseignement bilingue. In C. Degache \& S. Garbarino (Eds.), Actes du colloque IC2012. Intercompréhension: compétences plurielles, corpus, intégration. Université Stendhal Grenoble 3.

García, O.; \& Leiva, C. (2014). Theorizing and enacting translanguaging for social justice. In A. Blackledge \& A. Creese (Eds.), Heteroglossia as practice and pedagogy (pp. 199-216). Dordrecht: Springer.

Giles, H.; \& Niedzielski, N. (1998). 'Italian is beautiful, German is ugly'. In L. Bauer \& P. Trudgill (Eds.), Language myths (pp. 85-93). London: Penguin.

Golubović, J.; \& Gooskens, C. (2015). Mutual intelligibility between West and South Slavic languages. Russian linguistics, 39, 3, 351-373.

Gooskens, C. (2006). Linguistic and extra-linguistic predictors of Inter-Scandinavian communication. In J. van der Weijer \& B. Los (Eds.), Linguistics in the Netherlands, 23 (pp. 101-113). Amsterdam: John Benjamins.

. (2007). The contribution of linguistic factors to the intelligibility of closely related languages. Journal of Multilingual and Multicultural Development, 28, 6, 445-467.

. (2011). Asymmetrical intelligibility between the Scandinavian languages: experimental approaches. <http://let.rug.nl/gooskens/project/pdf/pres_kiel_2010.pdf> 
. (2013). Experimental methods for measuring intelligibility of closely related language varieties. In R. Baylay, R. Cameron, \& C. Lucas (Eds.), The Oxford Handbook of Sociolinguistics (pp. 195-213). Oxford: Oxford University Press.

Gooskens, C.; \& Bezooijen, R. van (2006). Mutual comprehensibility of written Afrikaans and Dutch: symmetrical or asymmetrical? Literary and Linguistic Computing, 23, 543-557.

Gooskens, C.; Bezooijen, R. van; \& Heuven, V. J. van (2015). Mutual intelligibility of Dutch-German cognates by children: the devil is in the detail. Linguistics, 53, 2, 255-283.

Gooskens, C.; \& Heeringa, W. (2004). The Position of Frisian in the Germanic Language Area. In D. Gilbers, M. Schreuder, \& N. Knevel (Eds.), On the boundaries of phonology and phonetics (pp. 61-87). Groningen: University of Groningen.

Gooskens, C.; \& Heuven, V. J. van (2017). Measuring cross-linguistic intelligibility in the Germanic, Romance and Slavic Language Groups. Speech Communication, 89, 25-36.

Gooskens, C.; Heuven, V. J. van; Golubović, J.; Schüppert, A.; Swarte, G.; \& Voigt, S. (2018). Mutual intelligibility between closely related languages in Europe. International Journal of Multilingualism, 15, 2, 169-193.

Grin, F. (2008). L’intercompréhension, efficience et équité. In V. Conti, \& F. Grin (Eds.), S’entendre entre langues voisines: vers l'intercompréhension (pp. 79-109). Chêne-Bourgh: Georg.

Haan, G. J. de (1997). Contact-induced changes in modern West Frisian. Us Wurk Tydskrift foar Frisistyk / Journal of Frisian Studies, 46, 61-89.

Haugen, E. (1996). Semicommunication: The language gap in Scandinavia. Sociological Inquiry, 36, 2, $280-297$.

Hélot, C. (2012). Linguistic diversity and education. In M. Martin-Jones, A. Blackledge, \& A. Creese (Eds.), The Routledge Handbook of Multilingualism (pp. 214-231). New York: Routledge.

Hilton, N.; \& Gooskens, C. (2013). Language policies and attitudes towards Frisian in the Netherlands. In C. Gooskens, \& R. van Bezooijen (Eds.), Phonetics in Europe: Perception and Production (pp. 139-157). Frankfurt am Main: P.I.E. - Peter Lang.

Hargitai, E.G. (2014). A situação da língua mirandesa - Bi- e plurilinguismo numa comunidade minoritária no Nordeste de Portugal. PhD tese: Budapest Eötvös Loránd University.

Hornsby, M. (2015). Revitalizing minority languages. New speakers of Breton, Yiddish and Lemko. Basingstoke: Palgrave MacMillan.

Laanen, F. (2001). The Frisian language in the Netherlands. In S. Trifunovska (Ed.), Minority Rights in Europe: European Minorities and Languages (pp. 67-84). The Hague: Asser Press.

Lewis, G.; Jones, B.; \& Baker, C. (2012). Translanguaging: Origins and development from school to street and beyond. Educational Research and Evaluation, 18, 7, 641-654.

Lüdi, G. (2007). The Swiss model of plurilingual communication. In J. D. ten Thije \& L. Zeevaert (Eds.), Receptive multilingualism: Linguistic analyses, language policies and didactic concepts (pp. 159-178). Amsterdam: John Benjamins.

Marwick, A.; \& Boyd, D. (2011). I tweet honestly, I tweet passionately: Twitter users, context collapse and the imagined audience. New Media \& Society, 13, 1, 114-133.

Nelde, P.H. (1978). Sprachkontakt und Sprachwechsel in Brüssel. Em P. Sture Ureland (Ed.), Sprachkontakt in Nordseegebiet (pp. 19-43). Tübingen: Max Niemeyer.

Nerbonne, J. (2001). Change, Convergence and Divergence among Dutch and Frisian. In Philologia Frisica anno 1999 (pp. 88-109). Ljouwert/Leeuwarden: Fryske Akademy.

O'Rourke, B.; \& DePalma, R. (2016). Language-learning holidays: what motivates people to learn a minority language? International Journal of Multilingualism, 14, 4, 332-340. 
O’Rourke, B.; Pujolar, J.; \& Ramallo, F. (2015). New speakers of minority languages: the challenging opportunity - Foreword. International Journal of the Sociology of Language, 231, 1-20.

O’Rourke, B.; \& Ramallo, F. (2013). Competing ideologies of linguistic authority amongst new speakers in contemporary Galicia. Language in Society, 42, 3, 287-305.

Pietikäinen, S.; \& Kelly-Holmes, H. (2011). Multilingualism in the periphery. Oxford: Oxford University Press. Poza, L. (2017). Translanguaging: Definitions, Implications and Further Needs in Burgeoning Inquiry. Berkeley Review of Education, 6, 2, 101-128.

Provinsje Fryslân (2015). De Fryske taalatlas 2015. Fryske taal yn byld. Ljouwert/Leeuwarden: Provinsje Fryslân.

Pujolar, J.; \& O'Rourke, B. (2018). Position paper: The Debates on "New Speakers" and "Non-Native" Speakers as Symptoms of Late Modern Anxieties over Linguistic Ownership (Unpublished). <https://www.academia. edu/35039330/Position_paper_The_debates_on_news_speakers_and_non-native_speakers_as_symptoms_of_late_modern_anxieties_over_linguistic_ownership>

Quarteu, R.; \& Frías Conde, X. (2002). L mirandês ũa lhéngua minoritaira na Pertual. Ianua, 2, 89-105.

Rebhein, J.; ten Thije, J. D.; \& Verschil, A. (2012). Lingua receptive (LaRa) - remarks on the quintessence of receptive multilingualism. International Journal of Bilingualism, 16(3), 248-264.

Rothman, J.; Cabrelli, J.; \& Boot, K. de (2013). Third Language Acquisition. In J. Herschensohn \& M. YoungScholten (Eds.), Handbook of Second Language Acquisition (pp. 372-393). Cambridge: Cambridge University Press.

Silva, A. I. (2017). E se eu fosse s/Surda? Implicações para a Educação Básica. In L. Menezes, A. P. Cardoso, B. Rego, J. P. Balula, M. Figueiredo \& S. Felizardo (Eds.), Olhares sobre a Educação: em torno da formação de professores (pp. 221-230). Viseu: Escola Superior de Educação de Viseu.

Suay, F. (2016). Com incidir en els usos lingüistics? Una perspectiva psicologica. Presented at the 24 Linguistics Colloquium "La promoció de l'ús de la llengua des del sistema educatiu: realitats i possibilitats" at the University of Barcelona.

Suay, F.; \& Sanginés, D. (2010). Sortir de l’armari lingüístic: una guia de conducta per a viure en català. Barcelona: Angle Editorial.

Swarte, F. (2011). Language attitudes of adults living in Friesland towards the Frisian language. Tese de mestrado, Rijksuniversiteit Groningen.

Swarte, F. (2016). Predicting the mutual intelligibility of Germanic languages from linguistic and extra-linguistic factors. PhD tese, Rijksuniversiteit Groningen.

Swarte, F.; Hilton, N. H.; \& Gooskens, C. (2013). Onderlinge Verstaandbaarheid tussen Noord- em Westlauwers Fries. Us Wurk. Tydskrift foar Frisistyk / Journal of Frisian Studies, 62, 21-46.

Ten Thije, J. D.; \& Zeevaert, L. (Eds.) (2007). Receptive multilingualism. Linguistic analysis, language policies and didactic concepts. Amsterdam: John Benjamins.

Trosset, C. S. (1986). The social identity of Welsh learners. Language in Society, 15, 2, 165-191.

Velasco, P.; \& García, O. (2014). Translanguaging and the writing of bilingual learners. Bilingual Research Journal, 37, 1, 6-23.

Vries, T. de (2010). De fersteanberens fan it Frysk foar dialektsprekkers. Us Wurk. Tydskrift foar Frisistyk / Journal of Frisian Studies, 59(3-4), 132-157.

Wolf, H. (2013). Wat makket it út oft it Frysk útsjert? <http://www.demoanne.nl/makket-it-no-ut-oft-itfrysk-utsjert/>

Wolff, H. (1959). Intelligibility and inter-ethnic attitudes. Anthropological Linguistics, 1, 34-41. 
Ytsma, J. (1995). Frisian as first and second language. Ljouwert: Fryske Akademy.

. (2007). Language and attitudes in Fryslân. In D. Lasagabaster \& A. Huguet (Eds.), Multilingualism in European bilingual contexts (pp. 144-164). Clevedon: Multilingual Matters.

Yuko, G. B.; \& Kenji, H. (2004). Bilingualism and Second Language Acquisition. In T. Bathis \& W. Ritchie (Eds.), The Handbook of Bilingualism and Multilingualism (pp. 114-132). Singapore: Blackwell Publishing. Zeevaert, L. (2007). Receptive multilingualism and inter-Scandinavian semicommunication. In J.D. ten Thije \& L. Zeevaert (Eds.), Receptive multilingualism. Linguistic analyses, language policies and didactic concepts (pp. 103-135). Amsterdam: John Benjamins. 
